\title{
LITERATURA E IDENTIDAD “AFROLATINAS” DEL CARIBE EN LOS ESTADOS UNIDOS
}

\author{
POR \\ WILLIAM LuIS \\ Vanderbilt University
}

La identidad "afrolatina" en el sentido norteamericano de la palabra se refiere a aquellas personas de descendencia afrohispana nacidas o criadas en los Estados Unidos. ${ }^{1}$ Ésta alude tanto a los escritores y las tradiciones que sus ancestros les han transmitido como a otros "latinos", y a que estas costumbres pasan a ser parte integral de una más extensa comprensión de la cultura nacional o de la comunidad caribeña, sin tener en cuenta la raza de la persona. Este concepto ampliado de la literatura e identidad "afrolatinas" de origen caribeño supone un contradiscurso para la comprensión homogeneizadora de la cultura, ya que expone relatos o narrativas acerca de quienes han sido históricamente marginados. Mientras que la historia está atada al pasado y evoluciona paulatinamente, la literatura presenta otra versión quizás aún más representativa de la historia, como lo proponen los autores y las obras que estos escriben. De hecho, la literatura es una manera de escribir o reescribir la historia. La identidad "afrolatina" del Caribe, en particular, sienta las bases para cuestionar la posición hegemónica a la cual se pueden adherir tanto "afrolatinos" como "no afrolatinos".

La presencia tanto de una identidad como de una literatura afrohispánicas en Hispanoamérica incluye a escritores de diversos países tales como Cuba, Puerto Rico, Colombia, México, Costa Rica, Panamá, entre otros, y defiende la existencia de las mismas características culturales entre los "afrolatinos" de Estados Unidos. Me refiero a los "afrolatinos" como descendientes afrohispánicos, cuyos padres nacieron y se criaron en un país americano de habla hispana y que luego emigraron a los Estados Unidos, donde nació o fue criada y educada su prole. Los afrohispanos están más atados a su cultura de origen y tienden a escribir en español; los "afrolatinos" han sido criados en

\footnotetext{
En español, "afrolatinos" son aquellas personas de descendencia africana que residen en Latinoamérica. En inglés, los "latinos" (Latinos/as) son descendientes de hispanos que residen en los Estados Unidos y sus hijos nacen o se crían en el país adoptivo. Los hispanos o afrohispanos se identifican con sus países de origen y los "latinos" o "afrolatinos" con la cultura de sus padres pero aún más con la de su país adoptivo. "Latino" y "afrolatino", entre comillas, se refieren al uso norteamericano de la palabra. Para un estudio de "latino", véase mi Dance Between Two Cultures.
} 
la cultura estadounidense y se expresan a sí mismos a través de la lengua y cultura de su país adoptivo, aunque algunos también hablan y escriben en español acerca de asuntos pertinentes al país de origen de sus padres. Y con el paso del tiempo, a medida que se sumergen en la política y sociedad del continente, los afrohispanos pueden llegar a formar parte de la comunidad "afrolatina".

Las personas afrocaribeñas escriben una asombrosa parte de la literatura "afrolatina", razón por la cual este estudio se centrará en su producción literaria. La emigración y el exilio de un gran número de personas del Caribe, principalmente de Cuba, Puerto Rico y República Dominicana, desde el siglo diecinueve hasta el presente, creó una considerable población diaspórica de afrodescendientes. Cuba y Puerto Rico eran las últimas colonias de España y seguían siendo territorios esclavizados con una inmensa población de africanos y descendientes de éstos. Muchos de los primeros viajeros eran exiliados políticos que dejaron su país de origen para continuar luchando en el país anfitrión en contra del sistema colonial español. Otros, trabajadores del sector del tabaco, emigraron cuando las compañías tabacaleras establecieron sus fábricas en ciudades como Tampa, Nueva York y Cayo Hueso. Con el paso del tiempo, estos y otros grupos se mezclaron con todos los sectores de la población dominante, incluyendo los afronorteamericanos y los de descendencia afrohispana, y negociaron así una identidad "afrolatina".

El modo cómo los afrohispanos que viven en los Estados Unidos negocian una identidad "afrolatina" llega a ser significativo cuando se estudian en profundidad las condiciones interculturales y raciales entre el país de origen y la tierra adoptiva. En el país de origen, a los ciudadanos afrodescendientes se les incita a que renuncien a su identidad negra y acepten una noción más amplia de lo que debería ser la nación y lo nacional. Es pertinente la obra de Benedict Anderson, Comunidades imaginadas: Reflexiones sobre el origen y la difusión del nacionalismo, ${ }^{2}$ pues al ciudadano lo define una comunidad intelectual selecta que equipara sus valores con aquellos que pertenecen a los de la nación emergente, obligando por tanto a las comunidades marginales a abandonar su sentido de diferenciación. El sistema de castas que funcionó durante el periodo colonial se convirtió en un componente fundamental del discurso nacional y contribuyó a perpetuar la superioridad blanca y la inferioridad negra. El blanqueamiento racial era el único camino a la movilidad social, económica y política. Hubo organizaciones de negros en los primeros capítulos de la historia de Cuba, tales como los cabildos o las sociedades de ayuda mutua, que se transformaron en las Sociedades de Color, pero todas buscaron las mismas oportunidades y los mismos estilos de vida que tenía la población blanca adinerada. Otras asociaciones, como los grupos religiosos, preservaron sus tradiciones, pero se consideraban "atrasadas" y marginales en relación al discurso dominante.

Comunidades imaginadas: Reflexiones sobre el origen y la difusión del nacionalismo Buenos Aires: Fondo de Cultura Económica, 1993. 
Las diferencias raciales en la isla se reforzaron y hasta aumentaron en el continente. En la Nueva York del siglo diecinueve había marcados contrastes entre las Logias Masonas: Los Caballeros de la Luz lo constituían dueños de fábricas; y el Sol de Cuba estaba integrado por cubanos afrodescendientes. Había otros grupos afrohispanos, como la Logia El Progreso (antes Logia Carlos Manuel de Céspedes) y Las Dos Antillas. Después, el Sol de Cuba se transformó en la Prentice Hall Lodge No. 38, con miembros de muchas de las comunidades negras de la ciudad. Los afropuertorriqueños Arturo Alfonso Schomburg, Francisco Gonzalo ("Pachín") Marín y Sotero Figueroa ocuparon puestos directivos en estas organizaciones.

Cuba tuvo incluso un partido político afrocubano, el Partido de los Independientes de Color (1908), bajo el liderazgo de Evaristo Estenoz y Pedro Ivonet. La meta era asegurar los derechos prometidos a los afrocubanos por su participación en la Guerra de Independencia (1895-1898). Sin embargo, después de la conformación de la República de Cuba en 1902 sus exigencias de igualdad se seguían ignorando. En 1912, a los miembros del partido se les acusó de incitar una rebelión y el ejército nacional asesinó a unos seis mil, una acción que desalentó cualquier otro movimiento de identidad negra en las generaciones futuras. El gobierno de los Estados Unidos, a través de la Enmienda Platt de la constitución de Cuba, contó con presencia militar para proteger los intereses estadounidenses y observar las actividades políticas de la isla, incluyendo las asociadas con el Partido Independiente de Color.

El control de los Estados Unidos sobre la colonia de Puerto Rico tuvo como consecuencia el desplazamiento de los puertorriqueños al continente. Este fue específicamente el caso después de la Segunda Guerra Mundial con Operación Manos a la Obra, un programa que brindaba incentivos económicos a las compañías que establecieran fábricas e industrializaran la isla. En lugar de esto, ocurrió una pesadilla demográfica cuando a muchos puertorriqueños, incluyendo un número significativo de afropuertorriqueños, los forzaron a abandonar la isla y a buscar empleo en el país adoptivo.

Los Cuentos puertorriqueños de hoy (1959), de René Marqués, reúnen las voces de los escritores de su generación que representan mejor el periodo que afectó y desplazó a ese desproporcionado número de afropuertorriqueños. "En el fondo del caño hay un negrito", de José Luis González, "Sol negro", de Emilio Díaz Valcárcel, y “Aguinaldo negro", de Edwin Figueroa, se atrevieron a sacar a la luz las condiciones raciales en la cultura de una isla que consideraba a todos los puertorriqueños iguales. El problema del racismo fue puesto en evidencia por Isabelo Zenón Cruz en su controvertido Narciso descubre su trasero (1975), una denuncia flagrante de los matices racistas de la cultura puertorriqueña, y, pocos años después, por José Luis González en El país de los cuatro pisos (1980), esbozo de las contribuciones hechas por los afropuertorriqueños.

La República Dominicana tiene una historia única. Declaró su independencia no de España sino de Haití en 1844, pero fue reincorporada como colonia española de 1861 a 1865. La raza se convirtió en un espacio de oposición para fomentar un sentido de

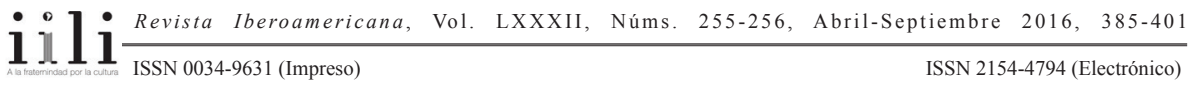


identidad nacional que el dictador Rafael Leónidas Trujillo explotó durante su régimen, de 1930 a 1961. Muchos dominicanos son descendientes tanto de esclavos llevados a La Española durante el periodo colonial español como de haitianos trasladados durante los veintidós años de ocupación. Con todo, los dominicanos reconocen una identidad indígena y no una negra, que ellos atribuyen a sus vecinos haitianos. Para solidificar su poder y preservar un sentido de dominicanidad, Trujillo orquestó la masacre de los haitianos que vivían a lo largo del Río Masacre, hogar también de muchos dominicanos de piel oscura. El masacre se pasa a pie (1974), de Freddy Prestol Castillo, y Cosecha de huesos, de Edwidge Danticat, se refieren a este trágico periodo de la historia de su país, que tuvo como resultado la muerte de unos veinte mil haitianos. Por ello, la identidad dominicana se basa en ser indígena y no negro o haitiano, aunque las dos naciones compartan un ancestro africano común.

El contacto entre la República Dominicana y los Estados Unidos se puede rastrear desde la ocupación estadounidense del país, entre 1916 y 1924, y los intercambios que tuvieron los dominicanos con los Estados Unidos, como los de la familia de Francisco Henríquez Ureña y sus hijos Max, Pedro, Francisco y Camila. La novela de Julia Álvarez, En el nombre de Salomé, narra partes de este importante periodo de la República Dominicana, que comienza con la vida de la poeta nacional del país, el matrimonio de Salomé Ureña con Francisco Henríquez y Carvajal, quien más tarde llegó a ser presidente de la República (1916). En Literatura dominicana en los Estados Unidos (2001), Daisy Cocco de Filippis y Franklin Gutiérrez hacen referencia a la familia Henríquez Ureña así como también a otros primeros viajeros como Fabio Fiallo, Manuel Florentino Cestero, Jesusa Alfau Galván de Solalinde y Gustavo Bergés Bordas, entre otros, y demuestran así el contacto continuo entre las dos naciones. Trujillo controlaba el país como si fuera su propia plantación, pero algunos dominicanos fueron capaces de dejar su tierra natal durante su mandato. La emigración se incrementó luego de su ejecución, y siguió en aumento después de la invasión estadounidense en 1965, cuando muchos viajaron a ciudades caribeñas como Nueva York.

Hispanos y afrohispanos tienden a asociarse más estrechamente con sus grupos nacionales o lingüísticos. Como extranjeros, experimentan el prejuicio lingüístico del angloparlante monolingüe, que exige total conformidad, ya que los recién llegados no concuerdan con su "comunidad imaginada". Y a los afrohispanos y "latinos" se los expone a la categorización racial, la misma que los afrodescendientes han tenido que soportar. Con la tensión racial que estalló en las décadas de los años cincuenta y sesenta, la cumbre de los movimientos de los Derechos Civiles y el Black Power, los inmigrantes de piel oscura tuvieron más dificultades al navegar por la sociedad dominante que sus compatriotas de piel más clara. Y como en el siglo anterior, se los acogió y encontraron refugio en la comunidad afronorteamericana. Esta creciente comunidad, con su complexión racial y complejidades, está redefiniendo lo que es ser negro en los Estados Unidos. 
La identidad y literatura "afrolatinas" aluden a la política racial presente en el país adoptivo, pero sin obviar su presencia en el lugar de origen. Arturo Alfonso Schomburg se destaca como la primera y más importante figura "afrolatina" que construyó un puente entre Cuba, Puerto Rico y los Estados Unidos. Como miembro de Las Dos Antillas Political Club se opuso al control de España sobre Cuba y Puerto Rico. Se dedicó luego a promover los logros de las personas afrodescendientes y a recopilar sus trabajos. Es autor de Plácido a Cuban Martyr (1909), una obra breve pero importante acerca de la ejecución de los poetas afrocubanos que presuntamente planearon la Conspiración de la Escalera (1844); fue cofundador, con John Edward Bruce, de The Negro Society for Historical Reserch (1911); y coeditor, con Daniel Alexander Payne Murray, de la Encyclopedia of the Colored Race (1912). Aunque Schomburg y otros más promovieron la igualdad racial expuesta por José Martí, era consciente de las divisiones raciales existentes en su país y en el extranjero, de modo que dedicó su vida a celebrar los logros de las personas de color. Es recordado por ser un distinguido bibliófilo de obras afronorteamericanas y una figura influyente durante el Harlem Renaissance.

El compatriota de Schomburg, Jesús Colón, fue uno de los primeros en escribir acerca de Puerto Rico y la problemática racial en los Estados Unidos. Aunque tanto él como Bernardo Vega eran trabajadores del sector tabacalero y creían en la causa socialista, Colón era claramente de asendencia afropuertorriqueño y fue tratado como un afronorteamericano. Sin lugar a dudas Colón era consciente de su tez oscura en un país que juzga a la persona por el color de su piel. En A Puerto Rican in New York and Others Sketches (1961), Colón expresa sus experiencias en la urbe norteamericana. En "The Mother, the Young Daugther, Myself and All of Us", ${ }^{3}$ Colón, mientras tomaba café en un lugar público muy frecuentado, oía por casualidad una conversación en la cual la madre alentaba a su hija para que ocupara el asiento disponible junto a él, y la hija respondía indicándole a la madre que no se sentaría al lado de un "negro". ${ }^{4}$ Las acciones de la hija muestran una lección aprendida en su lugar hogareño o en su comunidad. Sorprendentemente, la madre no corrige el comportamiento de su hija, lo cual refleja su propia conducta y educación. El incidente le sucedió a Colón, pero el "nosotros" al cual va referido el título ("All of Us") queda a la imaginación del lector. Conocemos la identidad de la madre, de la hijita y quién es yo, pero ¿quiénes son "todos nosotros"? El pronombre de la primera persona del plural se refiere a él y, quizás, a todos los que son como él, lo cual indica que nosotros, a quienes pueden llamar "negros", somos susceptibles de discriminación racial. El improperio que la hija enunció es una palabra que la madre y el resto de los clientes en el café, y por extensión la sociedad, había

La madre, la hijita, todos nosotros y yo [N. del T.].

4 "Negro", entre comillas, traduce la expresión, ofensiva, "nigger". En adelante, cuando aparezca la palabra "negro" entre comillas, recuérdese que equivale al término inglés mencionado [N. del T.]. 
pronunciado con anterioridad. Consideremos que solo hay un asiento disponible junto a Colón, el cual permanece desocupado antes y después del tiempo de la narración.

El clásico Por estas calles bravas, de Piri Thomas, expone el prejuicio racial común en la sociedad de Puerto Rico, silenciado por muchos a fin de proyectar una noción de unidad o de puertorriqueñidad en la comunidad puertorriqueña. Sin lugar a dudas, la raza es un problema que contamina a la familia puertorriqueña. Piri le confiesa al lector que, al igual que su padre, él era el miembro de piel más oscura en la familia y se siente discriminado, una acusación que su madre y hermanos niegan. Piri se refiere a su núcleo familiar y a la sociedad puertorriqueña en general. A este respecto, la novela refleja una realidad en Nueva York, pero el lector se puede preguntar acerca de la reacción de la familia si la misma realidad se presentara en Puerto Rico. La novela parece indicar que las mismas condiciones se repetirían en la isla; la madre y la sociedad serían igual de convincentes para desestimar la acusación y el conflicto del protagonista sería entonces aún mayor al contextualizar su aislamiento. El enfrentamiento de Piri con su familia y con su comunidad le permite identificarse con su amigo afronorteamericano Brew, con quien viaja a donde considera que es el origen de la tensión racial, el Sur. Experimenta así cómo se trata a los afronorteamericanos en esa parte de Estados Unidos. El descenso a los círculos más bajos de la versión estadounidense del Infierno de Dante valida lo que aprendió y presenció en su propia familia.

El puente entre las comunidades afronorteamericanas y las afropuertorriqueñas también lo cruzó uno de los controvertidos líderes del Young Lords Party, Felipe Luciano. Luciano comprendió claramente que el destino del pueblo puertorriqueño en Nueva York, y en particular el de los afrodescendientes, estaba ligado al destino de los afronorteamericanos. El cortometraje Right On! (1970), con Gylan Kain y David Nelson, muestra cómo los Last Poets ${ }^{5}$ celebran su negritud a través de la poesía, un problema de identidad que a Luciano le ayudaron a resolver sus hermanos afronorteamericanos. Luciano comprendió también que su propia causa era mucho más grande y que incluía a todos los puertorriqueños. En la película, Luciano recita "Jíbaro/My Pretty Nigger", "Hey Now" y "Puerto Rican Rhythms". El primer poema, "Jíbaro", del cual podría decirse que es el mejor, resalta la búsqueda puertorriqueña de identidad a través de un lenguaje afronorteamericano. Luciano considera que los puertorriqueños son negros y emplea el término "negro" para el "jíbaro" marginado, de quien el orador se apropia como símbolo de la diáspora puertorriqueña. Aunque el poema empieza en su lengua de origen, el español, salta a la lengua extranjera y se sumerge en lo subterráneo del sistema de metro neoyorkino, donde busca al jíbaro en una interpretación afronorteamericana del inglés. El jíbaro no puede escapar, pues pertenece a la voz poética en tanto repite "Y

Últimos Poetas [N. del T.]. 
nunca te dejaré ir", y concluye con una expresión que refleja el lado afronorteamericano de la identidad afrolatina, "nunca mi negro". 6

El "Nigger Reecan Blues" de Willy Perdomo, que cuenta con los mismos términos lingüísticos y culturales empleados por Luciano, expresa también cómo los puertorriqueños de piel oscura definen su identidad mientras viven en una sociedad que no distingue entre tonalidades de blanco o negro. Uno de los interlocutores, un afronorteamericano racialmente oprimido, le informa a su amigo puertorriqueño que, a pesar de su creencia en reivindicar una identidad nacional puertorriqueña, en los Estados Unidos él es otro negro más. Willy, en su defensa, reconoce que el taxista y la dama que aguantaba con fuerza su bolso lo trataron como si él fuera negro. Y, aceptara o no su negritud, sugirió que un Spic $^{7}$ es también un negro.

Las estructuras tradicionales de la negritud llegaron a ser problemáticas con la experiencia puertorriqueña. Esmeralda Santiago puede pretender cierta negritud, como lo expresa en el atractivo apelativo por el cual es conocida la protagonista de su Cuando era puertorriqueña, Negri, pero ella fue capaz de superar muchos de los obstáculos que marcan a las personas de color, lo cual podría explicar el número relativamente bajo de autores "afrolatinos". Ella y otros autores, como Judith Ortiz Cofer, intentan negociar una comprensión más amplia de negritud, pero hay un pequeño margen de comparación entre estos autores, que tienden a idealizar la tierra natal puertorriqueña, y la experiencia de los escritores nuyorriqueños, ${ }^{8}$ que resolvieron sus problemas de identidad aceptando las severas condiciones raciales de la ciudad de Nueva York. Esta otra cara la representa el título de la muy citada obra de Tato Laviera, La Carreta Made a U-Turn (1992), en la cual se sugiere que el retorno a la noción idealizada de Puerto Rico ya no es una opción. Esta decisión se hace explícita en los últimos versos de "A Lower Eastside Poem” (1987) de Miguel Piñero:

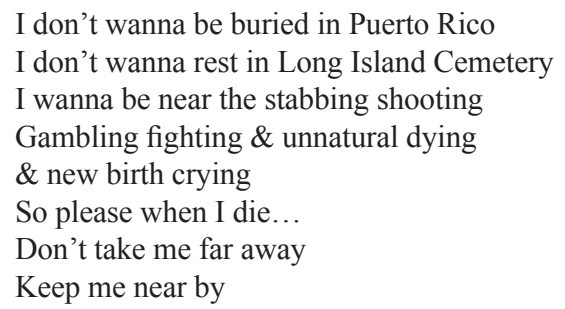

7 Término ofensivo usado para referirse a los descendientes de hispanoamericanos radicados en Estados Unidos [N. del T.].

8 Nuyorican en el original inglés. Neologismo producto de la combinación de New York con Puerto Rican. Los Nuyorican son los puertorriqueños que viven en Nueva York [N. del T.]. 
Take my ashes and scatter them thru out The Lower East Side...

[No quiero ser sepultado en Puerto Rico

No quiero reposar en el Cementerio de Long Island

Quiero estar cerca de las cuchilladas y balaceras

Las peleas de juego y los moribundos de causa no natural

Y el llanto de la nueva vida

Entonces por favor, cuando muera...

No me lleven lejos

Manténganme cerca

Tomen mis cenizas y espárzanlas a lo largo

Del Lower East Side ...] (5)

Santiago y Ortiz Cofer han hecho de su país adoptivo su hogar, pero sus obras representan una conexión con una infancia puertorriqueña absenta de categorizaciones raciales. En algunos aspectos, ese pasado estuvo prohibido para los escritores nuyorriqueños que fueron acusados de no ser puertorriqueños "reales", tal y como se vislumbra en el largometraje Piñero (2001), donde el personaje principal y sus amigos regresaron a la isla para luego ser tratados como extranjeros por sus compatriotas. Piñero los acusa de ignorar su propia identidad y de estar ciegos ante el control de los Estados Unidos sobre la isla. Por otro lado, la novela When the Spirits Dance Mambo (2002), de Marta Moreno Vega, subraya algunos de los conflictos evidentes en la familia de Piri Thomas; su hermana Socorro y su madre son de piel clara, y la protagonista, su hermano Chachito y su padre son de tez oscura. La abuela de la protagonista, Luisa, descendiente de María de la O., de Loiza Aldea (una conocida ciudad afropuertorriqueña), alega ser una esclava -"una africana de verdad"-, que representa el espiritismo y la religión africana en la cultura puertorriqueña. El aspecto "afrolatino" de la cultura caribeña está presente en la música latina, las religiones afrocubana y afropuertorriqueña en Nueva York, y hacia el final de la novela en su amiga afronorteamericana Donna Stokes. Aunque el señor Bloomstein se burla del acento de la protagonista, cuando ésta sale corriendo del salón de clase Donna se ausenta también y le asegura a su amiga que el acento español es una marca cultural que ella quisiera imitar. Daughters of the Stone (2009), de Dahlma Llanos-Figueroa, narra las vidas de mujeres afropuertorriqueñas y sus historias de supervivencia.

Podría decirse que Tato Laviera es el mejor de los escritores en reconocer que pertenece a las culturas de los Estados Unidos y Puerto Rico, y más recientemente a ninguna, pues su "Nideaquínideallá" es un término que indica tanto una dislocación

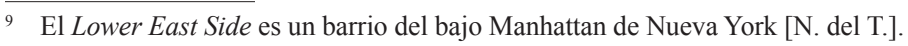

$111 \frac{\text { Revista Iberoamericana, Vol. LXXXII, Núms. 255-256, Abril-Septiembre 2016, } 385-401}{\text { ISSN 0034-9631 (Impreso) }}$ 
como una reconfiguración geográfica, lingüística y transcultural. Como he afirmado en otra parte, un "no lugar" se convierte en un hogar con sus propias identidades híbridas. Pero Laviera, quien escribe en español, inglés y spanglish, se enfrenta al problema racial en el lugar de origen y en la tierra adoptiva. Laviera se opone a la ignorancia racista de la cultura puertorriqueña en su "Tesis de Negreza" sobre "Negro bembón", una canción y un poema acerca del asesinato de un negro belfo cometido por un blanco puertorriqueño, que irónicamente se hizo popular por los afamados músicos afropuertorriqueños Ismael Miranda y Rafael Cortijo. A pesar de que la canción se ha extendido en la cultura popular, y muchos la cantan y bailan independientemente de donde vivan, muy pocos puertorriqueños le prestan atención a la letra, la cual justifica el homicidio. Laviera reproduce la canción en su totalidad, pero intercala una respuesta en las estrofas, minando así el relato original de la canción. De hecho, Laviera desafía las clasificaciones raciales impuestas durante el periodo colonial que parecieron haberse infiltrado en la cultura puertorriqueña. Palabras y expresiones inventadas como "lobo", "albarazado", "carpa mulato", "cambujo", "tente en el aire", "no te entiendo" o "bembón" son peyorativas y solo sirven para humillar a los negros, así como lo sugiere la acción del policía cuando esconde su bemba y acepta la cultura blanca. Laviera termina su poema con un sentido de orgullo racial nada diferente al que proclaman aquellos "afrolatinos" que viven en Nueva York.

Los poemas "afrolatinos" de Laviera son un testimonio de la solidaridad puertorriqueña hacia la cultura afronorteamericana, no como extranjeros, sino desde dentro. Cuando Laviera comenzó a celebrar su identidad "afrolatina", Nueva York se había convertido en otra ciudad del Caribe con un significativo componente "afrolatino". Esto se hace evidente en la popularidad de la música latina y se resalta en la novela Los reyes del mambo tocan canciones de amor, de Oscar Hijuelos, y en el largometraje homónimo, que cuenta con la participación de Celia Cruz y Tito Puente, y también con la de otras importantes figuras de la época que no aparecen en la película como Chano Pozo y Arsenio Rodríguez. Los poemas de Laviera son ricos en ritmos caribeños y en cultura afronorteamericana, un espacio que comparten los afropuertorriqueños y los afronorteamericanos. En "Preacher", esta figura religiosa da la bienvenida a los puertorriqueños a la congregación; y en "Harlem Elders Odes", el interlocutor reconoce estos pilares tradicionales de la comunidad afronorteamericana, a quienes debemos apreciar y no subestimar.

La escritura afrocubana es continua y se puede rastrear hasta el siglo diecinueve en las obras del esclavo poeta Juan Francisco Manzano, el poeta mulato Gabriel de la Concepción Valdés (Plácido) y, en el siglo veinte, en Martín Morúa Delgado, Nicolás Guillén, Nancy Morejón, Georgina Herrera y muchos otros más. Sin embargo, después del triunfo de la Revolución Cubana de 1959 que dio lugar a una nueva etapa en el complejo panorama político de la nación, el cual desató importantes olas de exiliados cubanos, pocos afrocubanos abandonaron la isla e incluso un pequeño número ha

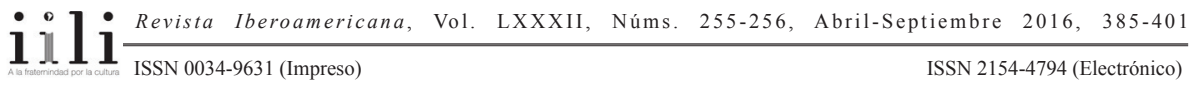


narrado sus experiencias. La inmensa mayoría de los exiliados fue en el periodo inicial era de la clase adinerada y descendiente de europeos. Sus hijos e hijas se convirtieron en miembros de una generación capturada acertadamente por Gustavo Pérez Firmat en su Life on the Hyphen (1994) y por Isabel Álvarez Borland en su Cuban American Literature of Exile (1998), pues los cubano-americanos negocian ambos lados de sus identidades separadas por el exilio. Incluso en la isla, a los escritores afrocubanos se les impedía que escribieran acerca de los problemas raciales; en lugar de eso, se los incitaba a promover una noción homogénea del ciudadano, aunque en ocasiones Nancy Morejón y Georgina Herrera ubicaron sus poemas en un contexto histórico aceptable. Sin embargo, otros artistas que vivían en el extranjero, como María Magdalena Campos Pons desde su residencia en Boston, se valieron de su negritud y raíces afrocubanas.

Existían afrocubanos viviendo en los Estados Unidos antes de la Revolución Cubana. Aunque algunos regresaron a Cuba cuando terminó la Guerra Hispanoamericana (18951898), otros permanecieron en el continente. Black Cuban, Black American: A Memoir (2000) es uno de los pocos trabajos que brindan un recuento de primera mano acerca de las vidas de los afrocubanos en Estados Unidos. Evelio Grillo narra las relaciones raciales en Cuba, pero principalmente las de su ciudad natal, Tampa, "La capital tabacalera del mundo", durante la década del treinta. Proporciona una arqueología de la ciudad, de su cultura y sus costumbres, incluso señala las calles de los "cubanos e italianos y españoles blancos adinerados" y aquellas al este de la Nebraska Avenue habitadas por afrocubanos, afronorteamericanos y algunos blancos pobres. Los cubanos trabajaban juntos en la industria tabacalera e interactuaban en los espacios públicos, pero tenían vidas sociales y religiosas separadas. La raza llegó a ser más fuerte que el idioma. Al principio, el idioma era una barrera entre los afrocubanos y los afronorteamericanos. Con el tiempo, las políticas raciales de los Estados Unidos se convirtieron en una fuerza que unió a todas las personas de color. Como sucedió con muchos afrohispanos y "afrolatinos" que vivían en los diferentes espacios geográficos, Grillo halló consuelo en la comunidad afronorteamericana.

La Revolución Cubana mejoró las vidas de muchos que no tenían acceso a la educación ni a la salud, pero la raza jugó un papel importante, ya que los negros seguían ocupando el grado más bajo de la escala social, económica y racial. Esto se hace más evidente cuando la mayoría de los cubanos blancos recibe remesas de sus parientes que viven en el extranjero y, como la economía de Cuba depende del turismo, hizo a los negros invisibles para el mercado de dinero en efectivo, excepto para el tradicional intercambio sexual. Sin embargo, como en el Contrapunteo cubano del tabaco y el azúcar (1940), de Fernando Ortiz, y El Monte (1954), de Lydia Cabrera, para mencionar dos obras seminales, se demuestra que algunos escritores cubano-norteamericanos han encontrado una voz en la cultura afrocubana. Sin lugar a dudas ésta ha sido la posición de escritores cubano-norteamericanos como Cristina García, quien se centra en el aspecto

$111 \frac{\text { Revista Iberoamericana, Vol. LXXXII, Núms. 255-256, Abril-Septiembre 2016, } 385-401}{\text { ISSN 0034-9631 (Impreso) }}$ 
africano de la cultura cubana, en particular en la Regla de Ocha, para enmarcar sus dos primeras novelas, Soñar en cubano y Las hermanas Agüero. Como se mencionó anteriormente, la cultura nacional no se limita al espacio geográfico de una nación, sino que la cultura caribeña es transnacional y está presente en el país adoptivo. De hecho, una indagación más detallada del tema muestra que la cultura del país adoptivo está ya presente en el país de origen. Esta idea se percibe en The Diaspora Strikes Back (2008), de Juan Flores, y es común a las ocupaciones estadounidenses de Puerto Rico, así como también a su influencia en Cuba y República Dominicana.

En Soñar en cubano, Pilar regresa a la isla y conoce su pasado familiar. Sin embargo, las estructuras de la cultura cubana que encuentra en la isla se reflejan en el país adoptivo: Santería, sentimientos anti-castristas o apoyo al régimen de Castro, por mencionar las más obvias. El viaje para visitar a su abuela, Celia, recuperar sus cartas y así tener acceso a su historia familiar es también una manera de comprender cómo el pasado de su familia en Cuba se entrecruza con su presente en los Estados Unidos. Y la curiosidad que Pilar siente hacia la Santería en Nueva York apunta a los rituales de Felicia en la isla y al relato de Herminia. En Las hermanas Agüero, la Regla de Ocha es más evidente y determina el curso de la novela. A Reina, quien trabaja como electricista en la región de El Cobre, la ciudad de la santa patrona de Cuba, la alcanzó un rayo y sufrió una transformación por la cual la piel de los demás se injertaba en la de ella. Le reza a la Virgen de la Caridad del Cobre, su madre espiritual, pero su padre, la deidad del rayo, es Changó. Al lector le queda la tarea de comprender por qué Ignacio asesinó a su esposa Blanca, posiblemente porque ella regresó embarazada del hijo de otro, a quien llamará Reina. La narración inicia y termina con la muerte de Blanca, el 8 de septiembre de 1948, el día de la santa patrona de Cuba, y el amante de ésta es un negro; la madre representa a Ochún y su padre a Changó.

Existen otros escritores cubanos que cuentan con las religiones africanas para desarrollar sus obras. Tal es el caso de Adrián Castro. El título de su poemario Cantos to Blood and Honey (1997) invoca los ingredientes utilizados para complacer a los Orishas. "In the Beginning" da la bienvenida a la llegada de las religiones africanas, la "fertilidad escondida en las caparazones y las piedras", y todo eso se define en "¡Crio-o-o-ollo! / Aquellos con un pie tallado en las islas / el otro pavoneándose ante Yoruba, Arará, / Kongo, Carabalí... / hijas de Ochún / hijos de Hebioso / tías y tíos de Ganga Nsasi / valientes hombres de Ekue Abasi". ${ }^{10}$ "The wedding between Spain \& Africa" presenta la transculturación de Cuba, pero la versión de la religión sincrética de la Santería según Castro: Olofin, Santa Bárbara, Nuestra Señora de la Misericordia, San Francisco de Asís, Nuestra Virgen de Regla, y sus correspondientes nombres africanos. Para Castro, África

\footnotetext{
10 "Fertility hidden in shells \& stones" [... "Crio-o-o-o-o-ollo!/Those with one foot chiseled in the islands/ the other strutting Yoruba, Arará,/kongo, Carabalí-/daughters of Oshun/ sons of Hebioso/Ganga Nsasi Owing aunts \& uncles/ brave men of Ekué Albasí (14)
}

$111 \frac{\text { Revista Iberoamericana, Vol. LXXXII, Núms. 255-256, Abril-Septiembre 2016, } 385-401}{\text { ISISSN 2154-4794 (Electrónico) }}$ 
está en Cuba, Puerto Rico y República Dominicana, así como también en la Pequeña Habana y en el Lower East Side de Manhattan. Su "Bilingual bicultural by U.S.A.", un poema acerca de sus identidades cubana, dominicana y norteamericana, y la mezcla de culturas que éstas representan, señala el espacio nuevo y diferente que ahora ocupan los “afrolatinos". En Wise Fish, Tales in 6/8 Time (2005), Castro mezcla la música, la lengua y las imágenes religiosas afrocaribeñas, en las cuales se combinan los espacios transculturales de Cuba, Haití y República Dominicana con los de Nueva York y Miami.

Debería ser claro a estas alturas que mientras que este estudio subraya una identidad y una literatura "afrolatinas" promovida por escritores "afrolatinos", también acentúa una literatura escrita por "latinos". Escritoras "latinas" como Esmeralda Santiago, Judith Ortiz Cofer y Cristina García son también, en un amplio sentido, "afrolatinas". Ellas hacen uso de lo que interpretan son las fuerzas de la negritud, que incluyen los componentes africanos de la identidad caribeña. Éste es también el caso de la escritora Julia Álvarez, cuya presencia en los Estados Unidos le permite comprender el aislamiento lingüístico y racial que experimentan los "afrolatinos", tanto en casa como en el país de origen de sus padres. A estos escritores no "afrolatinos" se los trata también como si fueran negros, y por ello comienzan a negociar una identidad racial inimaginable en su país de origen. En su ensayo "Black Behind the Ears", Álvarez reclama una identidad afrodominicana que es también la suya. En De cómo las muchachas García perdieron el acento, Yolanda busca en la República Dominicana una infancia pasada quizás antes de que perdiera su acento. A menos que sea necesario, los dominicanos adinerados no ven a sus criadas negras. Sin embargo, el aislamiento lingüístico, cultural y racial del alter ego de la autora la motivó a considerar las condiciones raciales presentes en la República Dominicana ignoradas por muchos habitantes y escritores. En el final físico de la novela, o el comienzo cronológico de la vida de la protagonista, ella encuentra y acoge a los dominicanos negros "invisibles", quienes también influyeron su vida. En Geographies of Home (1999), de Loida Maritza Pérez, los estudiantes universitarios llaman a la protagonista "negra" y acosan al personaje principal por su piel oscura. Este suceso la obliga a buscar refugio en el ambiente íntimo de su casa, donde, irónicamente, se expone al trauma familiar; se convierte en víctima de incesto en la supuesta santidad del hogar.

Las imágenes "afrolatinas" continuarán desafiando los discursos nacionales y transnacionales sobre la identidad, pues cada vez más escritores dominicanos exploran las tensiones raciales que presencian y experimentan en el continente, y por medio de esa óptica buscan maneras de interpretar la cultura de sus padres. Uno de los escritores que ha logrado esto de mejor manera es Junot Díaz, cuya colección de cuentos, Los Boys, se convirtió en éxito de ventas inmediato. Sus relatos están marcados por la raza, una problemática evidente en el título del cuento "Instrucciones para citas con trigueñas, negras, blancas o mulatas". Aunque el género es un problema, la raza se convierte en una

$111 \frac{\text { Revista Iberoamericana, Vol. LXXXII, Núms. 255-256, Abril-Septiembre 2016, } 385-401}{\text { ISSN 0034-9631 (Impreso) }}$ 
preocupación a la hora de salir con una mujer, pues cada una requiere de una estrategia particular. Sin embargo, en su La breve y maravillosa vida de Óscar Wao, Díaz entreteje dos espacios geográficos e identidades culturales en los cuales la raza hace que todo sea demasiado evidente. Óscar, a quien se le define como un dominicano de piel oscura y se confunde con un puertorriqueño, lucha por su identidad. La madre de Óscar, Belicia, es una dominicana negra, un adjetivo que en la República Dominicana se reserva más acertadamente a los haitianos, y su hija, Lola, la identifica como haitiana. Todos son descendientes de afrodominicanos, una terminología que los dominicanos rechazan en casa, pero que muchos dominicano-americanos están más dispuestos a considerar, dadas las condiciones raciales de su ciudad de residencia, según lo expresa Ginetta Candelario en su lectura de la exposición Black Mosaic en Washington D.C.

Escritores afrodominicanos como Blas Jiménez y Norberto James Rawlings, quienes en un momento $\mathrm{u}$ otro hicieron de Estados Unidos su hogar -Rawlings vive en Boston-, recurrieron a su experiencia estadounidense para subrayar los problemas raciales que muchos dominicanos rehúsan considerar, la cual es una posición expuesta también por Álvarez, Pérez y Díaz. Tanto Jiménez como Rawlings escriben en español para los lectores en su país de origen, así como también para aquellos en los Estados Unidos, y desafían la identidad nacional y geográfica "imaginada" de la República Dominicana. Su residencia en los Estados Unidos exige que ellos cuestionen el discurso homogéneo de la cultura nacional dominicana. En algunos aspectos, su esfuerzo no ha caído en saco roto, aunque los escritores nacionales siguen perpetuando una visión tradicional y occidental del ciudadano. Pero, colectivamente, han sentado las bases de otras interpretaciones para que futuros escritores recurran a ellas. En el poema "Los inmigrantes", Rawlings busca su identidad dominicana en sus ancestros anglocaribeños, una comunidad invisible a la configuración de la identidad del país. En La urdimbre del silencio (2000), junto con poemas acerca del exilio, la soledad, la memoria, la vegetación, entre otros, incluye "Genealogía”, un poema acerca de su pasado genealógico. En Patria portátil (2008), Rawlings insiste en su “otredad” cuando mezcla el español y el inglés y se refiere a su herencia.

Blas Jiménez fue la voz más fuerte que desafió la visión de la negritud que tenía la clase dirigente dominicana, la cual él consideró también un componente esencial de la identidad dominicana. En Caribe africano en despertar (1984), Jiménez reivindica su africanidad en "Como cimarrón bailando al caer la noche", poema acerca del esclavo encadenado coartado de su libertad; o como "Tu son Caribe", acerca de la música que el orador lleva dentro; y “Guerrillero", acerca de la libertad, la negritud y la auto-identidad.

Hay un número cada vez mayor de autores afrohispanos escribiendo en Estados Unidos y se adhieren también al concepto en expansión de negro o de "afrolatinos". Por ejemplo, Carlos Guillermo Wilson, de Panamá, ha escrito obras como Los mosquitos de Orixá Changó: Cuentos y poemas (2000) para el lector hispanoparlante. Su obra Los nietos de Felicidad Dolores (1991) narra las vidas de panameños descendientes

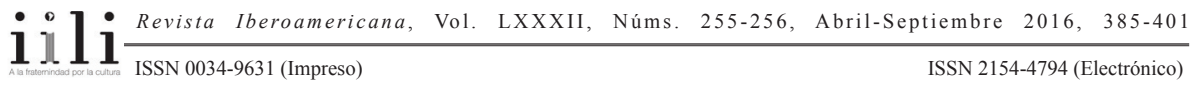


de antillanos que trabajaban en la Zona del Canal y que luego emigraron a los Estados Unidos. La novela se refiere a dos o más espacios transculturales.

La literatura "latina", y la "afrolatina" en particular, desafía los discursos y las posiciones predominantes de la identidad "afrolatina" y las sitúa en el centro de los problemas raciales, tanto en el país de origen como en la tierra adoptiva. Un componente central para ampliar la discusión acerca de la identidad y la literatura "latinas" se encuentra en The Afro-Latin@ Reader (2010), editado por Miriam Jiménez Román y Juan Flores. Esta es la primera antología acerca del tema que reúne obras importantes, algunas difíciles de encontrar, escritas por "latinos" y afrohispanos. Como historia colectiva, retrata las vidas de sus personajes desde la implantación de los africanos en las Américas hasta el presente. El contenido del libro va más allá de la literatura e incluye artículos, testimonios, música, religión, cine y otras manifestaciones populares de la cultura, con fuentes de primera mano y con bibliografía adicional. La compilación de un texto heterogéneo ayuda a indagar en las complejidades del tema, pero las definiciones de lo que son los "latinos" y los "afrolatinos" son imprecisas, ya que buscan identificar a estos individuos en una era muy anterior a la conformación de los Estados Unidos como nación, cuya cultura dio sentido al término "latino". Además, el popular y a veces malinterpretado término "Latinidad" no expresa, en mi opinión, una identidad "latina". En español el término está asociado más de cerca con el latín vulgar y con el desarrollo de las otras lenguas romances (el francés, el portugués, el rumano, el italiano y el catalán son las más populares) que con la población "latina" que se desea señalar y que vive en los Estados Unidos. Como he afirmado en otra parte, "latino" e hispano son términos que existen tanto en el español como en el inglés, pero su uso en inglés tiene un significado diferente al del español. La divergencia en la significación ocurre cuando un hablante utiliza un término en una lengua y se interpreta de manera diferente en la otra. Sin embargo, estas imprecisiones se añaden también a la complejidad del "latino" y asimismo se incluyen en la identidad "afrolatina".

Mientras que el presente estudio aborda la literatura "afrolatina" de origen caribeño en los países con una considerable población de afrodescendientes que residen en los Estados Unidos, hay otros grupos étnicos, raciales y culturales que han dejado su huella. Ciertamente, México, entre otros países, cuenta con una población afromexicana que está ganando consideración, aun cuando existe todavía un número importante de ciudadanos que rehúsa reconocer su presencia. México sigue el rastro de su ciudadanía negra hasta el periodo de la esclavitud, pero los afronorteamericanos que escaparon de la esclavitud también se abrieron paso al país vecino y algunos llegaron de otros países como Cuba, así como se describe en La muerte de Artemio Cruz (1962), de Carlos Fuentes. Octavio Paz se refiere al Pachuco en El laberinto de la soledad (1950), a quien el Premio Nobel considera una rareza en el panorama político de los Estados Unidos, así como los negros representan a los "otros". En este sentido, pachucos o chicanos, "afrolatinos" y afronorteamericanos, se pueden estudiar como ocupantes

$111 \frac{\text { Revista Iberoamericana, Vol. LXXXII, Núms. 255-256, Abril-Septiembre 2016, } 385-401}{\text { ISSN 0034-9631 (Impreso) }}$ 
de una posición similar en la sociedad estadounidense. Sin embargo, hay ejemplos de reconocimiento de un ancestro africano en la literatura chicana. El texto más conocido es el de Gloria Anzaldúa, Borderlands/La Frontera: The New Mestiza (1987), el cual discute las múltiples identidades de la voz poética del narrador, que incluye la negra, la mestiza y la africana, pues a ella la auxilia Yemayá, una deidad principal en una de las religiones africanas de Cuba. La identidad "afrolatina" y la negritud ayudan a negociar espacios de différence y différance (diferenciar y diferir) en el sentido derridiano de las palabras. Al hacer esto, la identidad "afrolatina" ocupa un escenario central en el discurso postmoderno.

Traducción de José Fernando Rubio Navarro

BiBLIOGRAFÍA

Álvarez, Julia. En el nombre de Salomé. Barcelona: Alfaguarra, 2002.

De cómo las muchachas García perdiero el acento. Nueva York: Vintage, 2007.

Álvarez Borland, Isabel. Cuban American Literature of Exile: From Person to Persona.

Charlottesville: U of Virginia P, 1998.

Anderson, Benedict. Comunidades imaginadas: Reflexiones sobre el origen y la difusión del nacionalismo. Buenos Aires: Fondo de Cultura Económica, 1993.

Anzaldúa, Gloria. Borderlands/La Frontera. San Francisco: Aunt Lute Books, 1987.

Candelario, Ginetta G. B. Black Behind the Ears: Dominican Racial Identity from Museum to Beauty Shop. Durham: Duke UP, 2007.

Castro, Adrián. Cantos to Blood and Honey. Saint Paul: Coffee House Press, 1997.

Cocco de Felippis, Daisy y Franklin Gutiérrez, eds. Literatura dominicana en los Estados

Unidos: Presencia temprana 1900-1950. Santo Domingo: Editorial Búho, 2001.

Danticat, Edwidge, Cosecha de huesos. Barcelona: Lumen, 2000.

Derrida, Jacques. La escritura y la diferencia. Barcelona: Editorial Anthropos, 1989. Díaz, Junot. Los Boys. Barcelona: Debolsillo, 2009.

La breve y maravillosa vida de Óscar Wao. Nueva York: Vintage, 2007.

García, Cristina. Soñar en cubano. Nueva York: Ballantine Books, 1994.

Las hermanas Agüero. Nueva York: Vintage, 1997.

Hijuelos, Oscar. Los reyes del mambo tocan canciones de amor. Madrid: Siruela, 1990.

Jiménez, Blas. Caribe africano en despertar. Santo Domingo: Manatí, 2006.

Jiménez, Román y Juan Flores, eds.TheAfro-Latin@Reader. Durham: Duke UP, 2010.

Llanos-Figueroa, Dahlma. Daughters of the Stone. Nueva York: Thomas Dunne Books, 2009.

Pérez, Loida Maritza. Geographies of Home. Nueva York: Viking, 1999.

Pérez Firmat, Gustavo. Life on the Hyphen: The Cuban-American Way. Austin: U of

Texas P, 1994.

$111 \frac{\text { Revista Iberoamericana, Vol. LXXXII, Núms. 255-256, Abril-Septiembre 2016, } 385-401}{\text { ISSNN 2154-4794 (Electrónico) }}$ 
Piñero, Miguel. Outlaw: The Collected Works of Miguel Piñero. Houston: Arte Público Press, 2010.

Rawlings, Norberto James. La urdimbre del silencio. Santo Domingo: Búho, 2000. Patria portátil. Santo Domingo: Editora Nacional, 200.

Santiago, Esmeralda. Cuando era puertorriqueña. Nueva York: Vintage, 1994.

Thomas, Piri. Por estas calles bravas. Nueva York: Vintage, 1998.

Vega, Marta Moreno. When the Spirits Dance Mambo. Nueva York: Three Rivers Press, 2004.

Wilson, Carlos Guillermo. Los nietos de Felicidad Dolores. Miami: Ediciones Universal, 1991.

Zenón Cruz, Isabelo. Narciso descubre su trasero. Humacao, PR: Editorial Furidi, 1979.

LECTURAS SUGERIDAS

Álvarez, Stephanie M. “¡¿Qué, Qué?!-Transculturación and Tato Laviera’s Spanglish Poetics”. Centro Journal 18/2 (2006): 25-47.

Bhabha, Homi K. Location of Culture. London: Routledge, 1994.

Cabrera, Lydia. El Monte. La Habana: Letras cubanas, 1993.

García, David. "Between Myth, Race and Marginality: Jesús Colón and the Afro Latino Condition". Tesis de doctorado. Vanderbilt University, 2004.

Luis, William. "Afro-Cuban/Latino Identity". Black Renaissance/Renaissance Noire 6.3/7.1 (2006): 145-51.

"Afro-Latino Identity and the Poetry of Tato Laviera". Review: Literature and Arts from the Americas 78 (2006): 31-41.

Dance Between Two Cultures: Latino-Caribbean Literature Written in the United States. Nashville: Vanderbilt UP, 1997.

"Latino Identify and the Desiring-Machine". The Other Latin@. Blas Falconer

y Lorraine M. López, eds. Tucson: Arizona UP, 2010.

Flores, Juan. Divided Borders: Essay on Puerto Rican Identity. Houston: Arte Público

Press, 1993.

From Bomba to Hip-Hop. Nueva York: Columbia UP, 2000.

The Diaspora Strikes Back: Caribeño Tales of Learning and Turning. Londres: Routlege, 2008.

Ortiz, Fernando. Contrapunteo cuban del tabaco y el azúcar. Caracas: Ayacucho, 1978. Piñeiro de Rivera, Flor. Arturo Schomburg: Un puertorriqueño descubre el legado histórico del negro. San Juan: Centro de Estudios Avanzados de Puerto Rico y el Caribe, 1989.

Schomburg, Arthur A. The Legacy of Arthur Alfonso Schomburg: A Celebration of the Past, a Vision for the Future. Nueva York: Schomburg Center for Black Culture, 1986.

11] $1 \frac{\text { Revista Iberoamericana, Vol. LXXXII, Núms. 255-256, Abril-Septiembre 2016, } 385-401}{\text { ISSN 0034-9631 (Impreso) }}$ 
Vega, Víctor Manuel. "An Analysis of Centrality of the Latino of African Descent: Understanding Afrocentric Agency in a Selected Segment of Contemporary Representative Latinos of African Descent". Tesis de doctorado. Temple University, 2001. 
